\title{
CONVERGÊNCIA CONTÁBIL NA ÁREA PÚBLICA: UMA ANÁLISE DAS PERCEPÇÕES DOS AUDITORES DE TCES, CONTADORES E GESTORES PÚBLICOS
}

\section{CONVERGENCE IN PUBLIC ACCOUNTING: AN ANALYSIS OF TCE'S AUDITORS, ACCOUNTANTS AND PUBLIC MANAGERS PERCEPTIONS}

\author{
JOÃO MARCELO ALVES MACÊDO \\ Mestre em Curso de Mestrado Acadêmico em Ciências Contábeis pela Universidade \\ Professor da Universidade Federal de Campina Grande, UFCG - Sousa, PB - Brasil \\ E-mail: joaomarcelo@ufcg.edu.br \\ LINO MARTINS DA SILVA \\ Livre-docente pela Universidade Gama Filho
Professor da Universidade do Estado do Rio de Janeiro, UERJ - Rio de Janeiro, RJ
Brasil \\ E-mail: smartins@uninet.com.br \\ MARCLEIDE MARIA MACEDO PEDERNEIRAS \\ Doutorado em andamento pelo PROPAD da UFPE \\ Mestre em Ciências Contabeis pela Universidade de Brasília \\ E-mail: marcleide@gmail.com
}

JORGE EXPEDITO DE GUSMÃO LOPES

Pós-Doutor pela University of Miami, U.M.S., Estados Unidos.

Doutor em Administração Escolar pela University of Miami, U.M.S., Estados Unidos. E-mail: je Pernambuco,

JOSÉ FRANCISCO RIBEIRO FILHO

Doutor em Controladoria e Contabilidade pela Universidade de São Paulo Professor da Universidade Federal de Pernambuco, UFPE - Recife, PE - Brasil. E-mail: francisco.ribeiro@ufpe.br

MARCOS GILSON GOMES FEITOSA Professor da Universidadé Federal de Pernambuco, UFPE - Recife, PE - Brasil E-mail: marcosfeitosa@dca.ufpe.br

\begin{abstract}
Resumo
A contabilidade pública vem passando por um processo de mudança desencadeado por inúmeros fatores, entre eles, a edição das NBC T SP e a da portaria do Ministério da Fazenda 184 de 25/08/2008. Fatos responsáveis pela mudança no foco da contabilidade pública, saindo do enfoque orçamentário para o patrimonial. Este artigo utilizou-se da estratégia indutiva para apreender as evidências por meio da percepção dos auditores do TCE, dos gestores e contadores públicos dos estados de Pernambuco e da Paraíba quanto à aplicabilidade dos conceitos true and fair view e accountability na contabilidade pública brasileira e especificamente os padrões internacionais, para os quais nossas normas irão convergir. A pesquisa teve uma etapa bibliográfica, respaldada pela aplicação de questionários estruturados a três grupos, alicerçados numa estratégia teórico-empírica, referendados estatisticamente por testes do Qui-Quadrado e de Kruskal-Wallis. Avaliou-se um total de 284 questionários divididos em 189 auditores de TCEs, 70 contadores públicos e 25 gestores públicos. Ao final do estudo, chega-se à conclusão de que para serem percebidas pela população em geral as boas práticas de gestão e de contabilidade pública, bem como as transformações resultantes da mudança do foco para a contabilidade patrimonial, necessitam de "desenvolvimento social", aliado a um maior grau de "transparência".
\end{abstract}

Palavras-chave: Accountanbility e True and fair view; Contabilidade pública; Convergência; IPSAS; NBC T SP.

\section{Abstract}

The public accounting system has been undergoing a process of change triggered by several factors, among them the issue of NBC T SP and the Order of the Ministry of Finance 184, 25.8.2008. Facts which are responsible for the change in focus of public accounting, moving from the budget approach to the patrimonial approach. This article used the inductive strategy to seize the evidence through the perception of TCE's auditors, managers and public accountants of the states of Pernambuco and Paraiba, concerning the applicability of the concepts true and fair view and accountability in public Brazilian accounting, specifically on international standards to which our standards will converge. The research had a literature stage, supported by structured questionnaires applied to three groups, rooted in a theoretical and empirical strategy, referred to statistical tests of Chi-square and KruskalWallis. We evaluated a total of 284 questionnaires, divided in 189 auditors from TCEs, 70 public accountants and 25 public managers. At the end of the study we came to the conclusion that in order to be perceived by the general population, good management practices and public accounting as well as transformations resulting from the change of focus towards patrimonial accounting, need "social development", together with a greater level of "transparency."

Key-worlds: Accountanbility e True and fair view; Public Accounting, Convergence, IPSAS; NBC T SP. 


\section{INTRODUÇÃO}

Diante das inúmeras discussões capitaneadas pelo Conselho Federal de Contabilidade (CFC), com a participação da sociedade organizada e dos diversos atores do processo, a contabilidade pública brasileira vem passando por mudanças, saindo do enfoque puramente orçamentário e voltando-se para a chamada teoria contábil, esta, sem muito esmiuçar, ligada umbilicalmente à essência do fato.

Alguns marcos denotam esta visão. Por exemplo, a realização das audiências públicas com vistas à edição das NBC TSP, que revelaram gradativamente o alinhamento da contabilidade pública com a ciência contábil e não apenas com o orçamento. Aquilo que não passava de um sonho pelos acadêmicos e pensadores da contabilidade brasileira, confirmou-se no dia 25 de agosto de 2008, quando o Ministério da Fazenda publicou a Portaria $n^{\circ} 184$, que dispõe sobre diretrizes a serem observadas pelos entes públicos visando torná-los convergentes com as Normas Internacionais de Contabilidade Aplicadas ao Setor Público (BRASIL, 2008a).

A essência da portaria acima referida denota a vontade de convergir a contabilidade atualmente praticada no país com a de países que adotam o padrão da IFAC, órgão responsável pela edição das IPSAS. O primeiro passo foi a criação das NBC T SP, com elas a ciência contábil passa a ter o controle da contabilidade praticada pelos entes públicos ou aqueles a ele equiparados, por analogia ou por deterem, administrarem ou aplicarem recursos públicos no desempenho de suas atividades. O segundo passo, e que aparenta ser um pouco complexo, é fazer com que as NBC TSP e demais peças legais norteadoras da contabilidade pública brasileira estejam aderentes aos padrões internacionais emanados do IFAC e que assim possam ser amplamente divulgadas, com vistas à aplicação uniforme em todo o território nacional.

Os estudos de Floriani (1998) mostram que, após exercer um papel estratégico no desenvolvimento econômico no período que abrange dos anos 30 aos anos 70, o Estado mergulhou numa crise durante os anos 80 . Essa crise se traduz por três tipos de problemas: primeiro, a crise fiscal, que ocasionou de uma só vez a perda da margem de manobra econômica do Estado e um aumento da dívida pública, associada às taxas inflacionárias elevadas, ao déficit interno crônico e a uma relativa estagnação do crescimento econômico; em seguida, por excesso de regulamentação econômica e de abuso de subsídios, o Estado tornou suas intervenções cada vez menos eficazes; finalmente, o sentimento generalizado de que os serviços públicos são administrados de uma maneira burocrática, ineficaz e rígida.

Em linhas gerais, existem dois conceitos/doutrinas que proporcionam a redução das variáveis negativas impactantes nos modelos de mensuração e disclosure das informações contábeis na gestão pública. São eles: accountability e true and fair view. O primeiro ainda não dispõe de uma tradução adequada para a língua portuguesa, mas 
denota algo como responsabilidade objetiva, transparência e prestação de contas. Já o segundo traduza-se em visão verdadeira e apropriada. A accountability provém dos Estados Unidos, onde encontra todo um panorama conceitual propenso à sua aplicação, tendo em vista o grau de desenvolvimento social hoje encontrado que the provê o sustentáculo necessário e funciona como mola propulsora. Já a true and fair view é algo que inspira mais dedicação e estudo para aplicação, em decorrência do maior tempo de concepção e dos inúmeros opositores, que centram suas discussões no aspecto subjetivo do termo. Isso se deve ao fato de esse grupo acreditar que uma demonstração contábil com maior grau de subjetivismo geraria riscos aos que iriam se utilizar dessa informação, porém, se pauta na visão verdadeira e apropriada do patrimônio da entidade.

Entretanto a visão de aplicabilidade de conceitos do setor privado ao setor público, não é unânime, já que Lopéz (1995, p. 142 apud SILVA, 2008a) mostra a existência de duas correntes: uma baseada em Hepworth e Vassalém (1984 apud SILVA, 2008a) e Anthony (1980 apud SILVA, 2008a), em que os conceitos, princípios e normas privados são claramente aplicáveis ao setor público; e outra de autores que divergem no pensamento, como Mautz (1991 apud SILVA, 2008a) e Montesinos, Garcia e Vela (1988 apud SILVA, 2008a), que acreditam na formulação de princípios contábeis próprios para o setor público que se adaptem às características dessas organizações e sirvam aos objetivos e requisitos da informação contábil pública.

Em especial no Brasil, utiliza-se do Estado de Direito como norteador das relações jurídicas. Esse é definido segundo Martinez (2006) “[...] como o Estado propenso ao direito: Estado de Direito é um estado ou uma forma de organização político-estatal cuja atividade é determinada e limitada pelo direito" (grifo do autor). Ao adotar-se o modelo acima citado, obriga-se o gestor público a ficar atrelado ao arcabouço legal existente, que o proíbe de se afastar dos princípios consubstanciados nesses diplomas legais. Porém, o que se verifica quando da aplicação das doutrinas acima descritas é um estado do common law, pautado nos costumes e que dispensa da tradução literal destes nos diplomas legais. Diante do que se apresenta, este estudo se propõe a estudar as variáveis envolvidas nesse processo.

Em decorrência das mudanças anunciadas para a contabilidade pública, verifica-se que não será uma simples mudança legal que determinará uma nova metodologia a se seguir, pelo contrário, é uma mudança que tem raízes culturais. Ao enumerarem-se as raízes, aponta-se a estrutura legal do país. Nos países onde se aplica o padrão IFAC predomina a estrutura common law (visão não legalista ou direito consuetudinário) e não o code law (visão legalista ou direito romano, onde o sistema legal é codificado e apresentam um maior grau de detalhamento das normas). Esse fato já aponta uma das barreiras para implantação desse padrão, visto que restringe a flexibilidade para as práticas contábeis.

Em nível mundial, a organização que emite os padrões de contabilidade pública é a International Federation of Accountants (IFAC), composta por organizações nacionais de profissionais de contabilidade e, até fevereiro de 2008, tinha emitido 26 (vinte e seis) padrões ou International Public Sector Accounting Standards (IPSAS). As NBCASP, que foram editadas no Brasil, de certa forma já se alinham em alguns momentos com as IPASAS. O Comitê Gestor da Convergência no Brasil (Resolução 
CFC 1.103/07, alterada pela 1.105/07), atualmente composto por representantes do CFC, do Ibracon (Instituto dos Auditores Independentes do Brasil), do Banco Central, da CVM (Comissão de Valores Mobiliários), da Susep (Superintendência de Seguros Privados) e do STN (Secretaria do Tesouro Nacional), conforme Portaria CFC nº37/08, é algo muito embrionário (REVOREDO, 2008).

No entanto sabe-se que em breve as NBC TSP estarão convergentes com as IPSAS, pois o GTCP (Grupo de Trabalho para a Convergência das NBC T SP às IPSAS da IFAC) trabalha para isso, e a primeira etapa, que é a tradução para o português das IPSAS, deverá sair em breve. Pretende-se, a partir daí, estruturar uma pesquisa que tenha como ponto de partida o fato das evoluções iniciarem em diversos momentos da história a partir de uma demanda social e que no setor público todos os atos são adstritos ao arcabouço legal em vigor. Busca-se então a aplicação de dois conceitos, accountabiliby e true and fair view, que juntos poderão vir a proporcionar, respectivamente, uma responsabilidade objetiva e uma maior transparência por parte do gestor público, bem como a garantia de que aquilo evidenciado é realmente a situação econômico-financeira do patrimônio da entidade. Para isso a pergunta que se coloca é a seguinte: qual a percepção dos auditores dos Tribunais de Contas Estaduais (TCEs), dos gestores públicos e dos contadores públicos acerca da aplicabilidade dos conceitos true and fair view e accountability à contabilidade pública brasileira, no processo de convergência com os padrões internacionais?

Diante da presente questão problema traçaram-se os seguintes caminhos para consecução das metas delineadas para a presente pesquisa. Como objetivo geral temse evidenciar a percepção dos auditores dos TCEs, dos gestores e contadores públicos dos estados de Pernambuco e da Paraíba quanto à aplicabilidade dos conceitos true and fair view e accountability na contabilidade pública brasileira, e sua influência no processo de convergência com os padrões internacionais de contabilidade aplicados ao setor público.

Foram criadas as seguintes hipóteses de estudo, visando auxiliar na resolução da questão-problema anteriormente formulada:

HOa - Neste contexto de convergência, e sob a ótica embasada pela percepção dos auditores dos TCEs, contadores e gestores públicos que conhecem accountability e true and fair view, os padrões internacionais de contabilidade NÃO se aplicam a contabilidade pública brasileira.

H1a - Neste contexto de convergência, e sob a ótica embasada pela percepção dos auditores dos TCEs, contadores e gestores públicos que conhecem accountability e true and fair view, os padrões internacionais de contabilidade se aplicam a contabilidade pública brasileira.

HOb - Neste contexto de convergência, e sob a ótica embasada pela percepção dos auditores dos TCEs, contadores e gestores públicos que conhecem accountability e true and fair view, esses dois conceitos/doutrinas NÃO se aplicam a contabilidade pública brasileira.

H1b - Neste contexto de convergência, e sob a ótica embasada pela percepção dos auditores dos TCEs, contadores e gestores públicos que conhecem 
accountability e true and fair view, esses dois conceitos/doutrinas se aplicam a contabilidade pública brasileira.

Esta pesquisa justifica-se e tem sua importância a partir do contexto vivido atualmente em função da necessidade de estudar-se o processo de convergência e do desencadeamento de inúmeras transformações iniciadas não apenas por se mostrarem importantes, mais sim por fazerem parte de um processo alicerçado num marco teórico e legal, que determina a convergência dos padrões contábeis do setor público brasileiro aos internacionais. Parte-se do pressuposto que ao adotarmos um padrão internacional, iremos nos deparar com inúmeros fatores que dificultarão este processo, e que por sua vez, serão responsáveis em especial pelo sucesso ou não desta transformação. Aliado a esta busca por identificar o processo de convergência, adota-se uma estratégia indutiva, pela qual se busca perceber tais influências a partir dos conceitos/doutrinas umbilicalmente ligados aos padrões internacionais, sendo estes o true and fair view e o accountability.

\section{PROCEDIMENTOS METODOLÓGICOS}

Este trabalho teve seu início a partir do desenvolvimento de uma pesquisa bibliográfica, numa perspectiva teórico-empírica, utilizando-se da dedução na etapa bibliográfica e da indução na pesquisa de campo, objetivando reunir evidências necessárias à consecução do objetivo precípuo.

Geograficamente este estudo foi delimitado a dois estados nordestinos: o da Paraíba e o de Pernambuco, e no que tange à esfera temporal, aos anos de 2008 e 2009. Em seu escopo, o trabalho está restrito à percepção dos grupos entrevistados, que trabalham diretamente com a contabilidade pública, e obedecendo à condição indispensável de se encontrarem atuando nos momento da pesquisa. Foram estabelecidas premissas objetivando minimizar os efeitos nocivos ao estudo, aos auditores públicos, a condição necessária era que estes integrassem as equipes de auditoria; já aos contadores ou auxiliares de contabilidade a condição era desempenhar suas funções junto à contabilidade pública; no caso dos gestores, a condição era estar tomando algum tipo de decisão no âmbito público, bastando apenas ter mandato eletivo, ser gestor de carreira ou ser indicado para tanto, onde teria função ou cargo de chefia.

$\mathrm{Na}$ coleta de dados foi utilizada a técnica do questionário estruturado, usando a escala Likert. Esta, por sua vez, é um método de construção de questionário, onde se busca a percepção do inquirido acerca do tema ou afirmativa. Nela o respondente deverá selecionar as respostas dentro do seguinte intervalo: (5) concorda totalmente; (4) concorda; (3) sem opinião/indiferente; (2) discorda; e (1) discorda totalmente (AMARO; PÓVOA; MACEDO, 2005).

Como métodos estatísticos utilizaram-se a estatística descritiva, testes estátisticos e a tabulação cruzada, para a análise dos dados, com o auxílio do aplicativo estatístico SPSS (Statistical Package for the Social Science) versão 11.0. 
Foram testadas as variáveis de conhecimento dos termos, aplicabilidade à gestão e à contabilidade pública brasileira. Tais variáveis foram analisadas a partir do teste não-paramétrico de Kruskal-Wallis, que substitui o teste ANOVA e verifica se k grupos independentes provêm da mesma amostra. 0 nível de significância admitido neste estudo foi de 5\%. Aplicou-se ainda o teste de Qui-Quadrado $\left(x^{2}\right)$, visando verificar se as respostas são ao acaso, quando da análise das respostas de cada grupo, eliminando a resposta 3 (que será considerada indiferente) e unindo as respostas "1" e " 2 " , construindo uma variável e do outro lado as respostas " 4 " e " 5 " , formando a outra variável.

\section{REVISÃO DE LITERATURA}

\subsection{TRUE AND FAIR VIEW}

Desde o início desta década é nítida a opção da sociedade atual por conhecer a aplicação dos recursos públicos, além de clara a opção para conhecer não só a qualidade do gasto como também o retorno efetivo dos recursos entregues aos administradores públicos a título de impostos e contribuições. Desse modo, é possível vislumbrar um cenário propenso a tornar as demonstrações cada vez mais fidedignas e, consequentemente, atender de modo efetivo às necessidades dos usuários, do gestor e do contribuinte-cliente. É nesse contexto que surge a doutrina do true and fair view, como o estudo que pode contribuir para a melhor evidenciação dos elementos patrimoniais das entidades públicas.

Essa doutrina filosófica surgiu na Europa no século XIX e, segundo Cunningham (2003 apud PINHEIRO; NAKAGAWA, 2004, p. 4), "a doutrina da true and fair view surgiu como produto da jurisprudência dos tribunais ingleses em 1844, como exigência de que as demonstrações contábeis deveriam se revestir das características de verdade e equidade [...]" (grifo do autor). Para Jreige (1998, p. 1), a legislação inglesa, em 1948, passou a exigir que as demonstrações financeiras fornecessem a true and fair view, visão verdadeira e justa, da situação dos negócios da empresa.

A Quarta Diretiva, emitida em 1978 pelo Conselho da antiga Comunidade Econômica Europeia, mostrou-se mais abrangente e trouxe regras de contabilidade no seu âmbito, quais sejam: (a) regras para a formatação do balanço e da demonstração de resultado, refletindo a tradição francesa e germânica; (b) exigências de divulgação; (c) regras de avaliação baseadas no custo histórico; e (d) a verdadeira e justa visão prevalece sobre a específica provisão onde as circunstâncias justificam isso (SOARES, 2005, p. 35).

Corroborando com as explicações acerca da Quarta Diretiva, Rodrigues e Pereira (2004 apud SILVA, 2009b), afirmam que a tradução correta do termo anglo-saxônico true and fair view seria imagem fiel, e surgiu pela primeira vez na Companies Act de 1947, que substituiu a expressão true and correct view que figurava na Companies Act de 1900. Para os profissionais daquela época, tratar de uma visão verdadeira e correta seria algo demasiadamente preciso para se refletir a prática contábil. E somente na década de 1970 é que o termo se reveste de propriedade e tem seu uso 
referendado, adquirindo especial importância na Inglaterra, auxiliando na fuga do legalismo puro evidenciado pelo primeiro draft da Quarta Diretiva de 1978 (SILVA, 2009b).

O Comitê de Pronunciamentos Contábeis (CPC) emitiu o Pronunciamento CPC00 , que trata do pronunciamento conceitual básico, estabelecendo a correlação às normas internacionais de contabilidade - "Estrutura para a Preparação e a Apresentação das Demonstrações Contábeis" (Framework for the Preparation and Presentation of Financial Statements) - (IASB), trazendo a tradução do termo true and fair view como sendo visão verdadeira e apropriada, explicando da seguinte forma no item 46:

46. Demonstrações contábeis são freqüentemente descritas como apresentando uma visão verdadeira e apropriada (true and fair view) da posição patrimonial e financeira, do desempenho e das mutações na posição financeira de uma entidade. Embora esta Estrutura Conceitual não trate diretamente de tais conceitos, a aplicação das principais características qualitativas e de normas e práticas de contabilidade apropriadas normalmente resultam em demonstrações contábeis que refletem aquilo que geralmente se entende como apresentação verdadeira e apropriada das referidas informações. (CPC-00, 2009)

Em decorrência desse fato específico, bem como da concepção deturpada que se tem nos dias atuais de justiça, e que se transformou numa das molas propulsoras deste trabalho, optou-se por seguir tratando o termo desta forma, qual seja, visão verdadeira e apropriada.

\subsection{ACCOUNTABILITY}

O termo accountability nos últimos anos é trazido para a administração como condição indispensável a uma boa gestão. Ele visa promover a aproximação entre a sociedade e o gestor público, visto que uma gestão que a tenha como princípio norteador estaria aproximando-se das práticas de promoção da participação social. Entretanto é preciso reconhecer que esse é um conceito afastado de nossa realidade, embora seja louvável todo o esforço para sua implementação. Para Mosher (1968, p. 7 apud CAMPOS, 1990, p. 33), o termo accountability pode ser visto como sinônimo de:

[...] responsabilidade objetiva ou obrigação de responder por algo: como um conceito oposto a - mas não necessariamente incompatível com responsabilidade subjetiva. Enquanto responsabilidade subjetiva vem de dentro da pessoa, a accountability, sendo uma responsabilidade objetiva, "acarreta a responsabilidade de uma pessoa ou organização perante outra pessoa, fora de si mesma, por alguma coisa ou por algum tipo de desempenho".

Portanto, accountability não corresponde à vontade exclusiva do gestor, mas corresponde a um sinal de alerta que na Lei de Responsabilidade Fiscal é denominado de "limite da prudência" cuja transgressão acarreta, além de uma simples sanção pecuniária, o sentido de responsabilização e o sentimento social de julgamento pleno pelas ações empreendidas.

Campos (1990, p. 33) explica que, inicialmente ao se tentar traduzir a accountability, ela era entendida como algo que advinha da evolução democrática de 
uma sociedade, propiciando uma evolução significativa no trato com a coisa pública e nos interesses dos diversos cidadãos, estando, assim, na contramão do que é proposto ao tentar simplificar algo bem maior, e que não deveria advir apenas de um mandato, como um programa, uma bandeira ou estratégia política, mas sim como a gestão de forma completa. O primeiro passo para o entendimento é proposto por Castro (2005, p. 70) ao afirmar que "accountability significa responsabilidade por prestar contas. No Brasil, prestar contas não é uma atitude natural, só se faz, quando faz, por força da lei." A fim de esclarecer essa função adstrita apenas à prestação de contas, a Lei de Responsabilidade Fiscal, em seu art. 58, delimita o escopo da prestação de contas.

Estudando as relações entre governança e accountability, Schedler (2000) esclarece o conceito de accountability, identificando suas dimensões e distintos significados e ênfases, distinguindo as duas conotações básicas que o termo accountability política suscita: a) a capacidade de resposta dos governos (answerability), ou seja, a obrigação dos oficiais públicos informarem e explicarem seus atos; e b) a capacidade (enforcement) das agências de accountability (accounting agencies) de impor sanções e perda de poder os que violaram os deveres públicos, concluindo que a noção de accountability é basicamente bidimensional: envolve capacidade de resposta e capacidade de punição (answerability e enforcement).

A IFAC (2001, p. 11) definiu o "the system by which organizations are directed and controlled", apontado no The Report of the Committee on the Financial Aspects of Corporate Governance 5 (the Cadbury report), e que resultou na definição de três princípios fundamentais da governance corporative: (a) openness; (b) integrity; e (c) accountability.

Diante desse pensamento verifica-se a necessidade de abrangência cada vez mais no que tange ao processo de mudança paradigmática do Estado brasileiro rumo às concepções voltadas às relações transparentes entre a sociedade e a classe política, sem desprezar os técnicos governamentais, que elaboram as políticas públicas e as estratégias de governo.

\subsection{NORMAS BRASILEIRAS DE CONTABILIDADE TÉCNICA - SETOR PÚBLICO E A CONVERGÊNCIA INTERNACIONAL}

As NBC TSP passaram por um processo de construção pautado não apenas no sistema participativo, mas na união de todos aqueles que fazem a contabilidade pública brasileira, desde profissionais até os órgãos e instituições envolvidas no processo, a exemplo do Tribunal de Contas da União. Elas estarão até 2010 alinhadas às International Public Sector Accounting Standards (IPSAS), que são os padrões internacionais de contabilidade pública emitidas pela International Federation of Accountants (IFAC).

Essa necessidade de praticar contabilidade e não apenas controle orçamentário, conforme aconteceu durante décadas, advém principalmente da expansão do conceito de accountability, em que os clientes dessa informação extrapolam as fronteiras nacionais. Daí aquela força coercitiva que se converte em dever, por parte do gestor público, de prestar contas e manter transparente as políticas fiscais, financeiras e 
macroeconômicas, bem como estarem "compreensíveis, interpretáveis e analisáveis por organismos estrangeiros ou supranacionais” (REVOREDO, 2008).

Um dos problemas que vem afligindo grande parte dos acadêmicos partícipes deste processo deve-se às resistências que são encontradas em alguns setores, sendo referenciado por Silva (2010, p.1), conforme abaixo:

\begin{abstract}
Podemos garantir que, mesmo estudando os processos de gestão, será muito difícil a implantacáo do que estamos denominando a "Nova Contabilidade" seja pela resistência de alguns setores da administração pública, seja pela blindagem de certas áreas em relação à abertura de suas informaçoes ou, ainda, pelo entendimento errôneo de alguns de que a Contabilidade deve atuar passivamente e só registrar o que lhe é encaminhado.
\end{abstract}

Este último problema certamente ocorrerá em setores que ao longo do tempo valorizaram os sistemas (SIAF - SIAFEM e outros) em que o setor de contabilidade no lugar de estudar a Ciência Contábil estava mais preocupado com os eventos, os códigos, as rubricas e as alíneas. Não temos dúvida de que a mudança virá a partir da conscientização de que a Contabilidade é a ciência que estuda o patrimônio.

Tal afirmação deve-se em função das dificuldades enfrentadas por Portugal, ao chegar a 13(treze) anos de implantação do POCP - Plano Oficial de Contas Públicas. Mesmo sem ser aplicado em todos os Estados, já se estudam alterações, embora ele fosse considerado um passo fundamental para o controle das contas públicas e estivesse em consonância com as diretrizes de controle do tratado da União Europeia.

No dia 21 de novembro de 2008, foram aprovadas em plenária do Conselho Federal de Contabilidade as NBCASP, sedimentando definitivamente a migração do foco no orçamento para patrimônio pela contabilidade pública brasileira. Vê-se neste fato uma decisão de aproximação com a ciência contábil, passando todos os fatos administrativos, que antes eram examinados e registrados por terem origem no orçamento, a serem examinados e registrados por produzirem alterações em algum elemento patrimonial. Essa proposição já constava regulamentada no diploma legal desde 1964, pela Lei $n^{\circ} 4.320$, e agora será necessário um estudo aprofundado dos artigos que tratam do processo de evidenciação contábil, em especial daqueles a partir do art. 83 (SILVA, 2008a). As NBC TSP aprovadas são as seguintes:

\begin{tabular}{|c|c|l|}
\hline \multicolumn{2}{|c|}{ NORMAS TÉCNICAS } \\
\hline NBC TSP & Resolução CFC & \multicolumn{1}{c|}{ Conteúdo } \\
\hline 16.1 & $1.128 / 2008$ & Conceituação, objeto e campo de aplicação \\
16.2 & $1.129 / 2008$ & Patrimônio e Sistemas Contábeis \\
16.3 & $1.130 / 2008$ & Planejamento e seus Instrumentos sob o Enfoque Contábil \\
16.4 & $1.131 / 2008$ & Transações no Setor Público \\
16.5 & $1.132 / 2008$ & Registro Contábil \\
16.6 & $1.133 / 2008$ & Demonstrações Contábeis \\
16.7 & $1.134 / 2008$ & Consolidação das Demonstrações Contábeis \\
16.8 & $1.135 / 2008$ & Controle Interno \\
16.9 & $1.136 / 2008$ & Depreciação, Amortização e Exaustão \\
16.10 & $1.137 / 2008$ & Avaliação e Mensuração de Ativos e Passivos em Entidades do Setor \\
\hline
\end{tabular}

Quadro 6: Audiência pública das Normas Brasileiras de Contabilidade Aplicadas ao Setor Público Fonte: Silva (2009a p. 354). 
Como fruto do trabalho do CFC, destaca-se a Portaria $\mathrm{n}^{\circ} 184$, de 25 de agosto de 2008, do Ministério da Fazenda, que deu o respaldo necessário ao processo de convergência ao resolver, em seu art. $1^{\circ}$ :

Art. $1^{\circ}$ Determinar à Secretaria do Tesouro Nacional - STN, [...], o desenvolvimento das [...] ações no sentido de promover a convergência às Normas Internacionais de Contabilidade publicadas pela International Federation of Accountants - IFAC e às Normas Brasileiras de Contabilidade aplicadas ao Setor Público editadas pelo Conselho Federal de Contabilidade - CFC, respeitados os aspectos formais e conceituais estabelecidos na legislação vigente. (grifo nosso).

Tais documentos, além de anunciar uma série de mudanças conceituais, visam promover maior aproximação entre a ciência contábil e a contabilidade pública. Com vistas a convergir as NBC TSP às IPSAS, foi elaborado e aprovado um calendário de ações e metas do GTCP, que é apresentado abaixo:

Até dezembro de 2008 - Definição de GEs; nivelamento do GTCP; distribuição de versão em inglês

Até março de 2009 - Disponibilização das IPSAS em Português validadas pelos GEs*

De abril a dezembro de 2009 - Elaborar minutas das NBCASP convergidas*

Até dezembro de 2010 Disponibilizar, apresentar e discutir as NBCASP convergidas

Até dezembro de 2011 - Capacitar os profissionais sobre conteúdo e aplicação das NBCASP Convergidas

Janeiro de 2012 - Entrada em vigor das NBCASP Convergidas aos Padrões Internacionais IPSAS

* Essas etapas estão atrasadas em função da complexidade da tradução das IPSAS.

Quadro 8: Cronograma Resumido do GTCP

Fonte: Adaptado de Ribeiro Filho (2008)

\subsection{DIMENSÃO CULTURAL E A INFLUÊNCIA NO PROCESSO DE CONVERGÊNCIA}

É fato referenciado por diversos estudiosos que a cultura interfere no processo de padronização de cada país, sabe-se, no entanto, que essa interferência tem maior ou menor intensidade, em decorrência de fatores exógenos ao processo em si, quer seja em virtude do modelo da dicotomia entre exploração/colonização, quer seja em virtude da característica da posição geográfica no globo terrestre, similitudes verificadas, por exemplo, nos povos anglo-saxônicos. Um dos estudos que pode referendar essas influências é o de Weffort (2005, p. 139), quando assevera assim:

[...] cultura tem sido vista como uma das causas prováveis para as diferenças contábeis internacionalmente, sendo capaz de exercer influência nas normas e práticas contábeis, tanto diretamente, afetando o comportamento do contador e dos usuários das demonstrações contábeis, como indiretamente, por intermédio das principais instituições do país (por exemplo, sistema 
econômico, político e legal).

Nessa linha de pensamento têm-se referenciado estudos, como os de Hofstade (1980; 1983; 1987; 1991) e Gray (1988). Hofstade (1983, p. 21 apud OLIVERAS; AMAT, 2004) define cultura como sendo "the collective programming of the mind which distinguishes the members of one human group from another". Hofstade (1983, p. 21 apud OLIVERAS; AMAT, 2004) identificou quatro dimensões de cultura, que são: (1) Power distance; (2) Uncertainty avoidance; (3) Individualism; e (4) Masculinity.

Rodrigues e Pereira (2004) afirmam que podem ser elencados alguns inimigos, ou seja, fatores restritivos à aplicação completa da "imagem fiel", dentre os quais se apresenta: (a) o Fisco em relação ao valor e medida de alguns elementos do patrimônio; e (b) o conservadorismo e o princípio da competência, que dependem da importância e da cultura do país (SILVA, 2009b).

\section{APRESENTAÇÃO E ANÁLISE DOS DADOS}

Conforme apresentado, a pesquisa teve seu escopo limitado à percepção de três grupos que são envolvidos diretamente com a contabilidade pública. Serão apresentadas as respostas dos auditores públicos, seguidas das dos contadores públicos e, por fim, as dos gestores. Sendo assim divididos, 189 (cento e oitenta e nove) Auditores Públicos de TCE's, 70 (setenta) contadores públicos e 25 (vinte e cinco) gestores públicos conforme tabela 1, abaixo:

\begin{tabular}{c|c|c|c|c}
\hline & & \multicolumn{2}{|c|}{ ESTADO } & Total \\
\hline \multirow{2}{*}{ GRUPO } & Auditores Públicos & 108 & 81 & 189 \\
\hline & Contadores Públicos & 30 & 40 & 70 \\
\hline & Gestores Públicos & 10 & 15 & 25 \\
\hline Total & & 148 & 136 & 284 \\
\hline
\end{tabular}

Tabela 1: Crosstabulation Grupo Respondente e Estado de origem.

Fonte: Elaboração própria, a partir dos dados da pesquisa.

De forma condensada na Tabela 3, apresenta-se um resumo das respostas da segunda parte do questionário. 


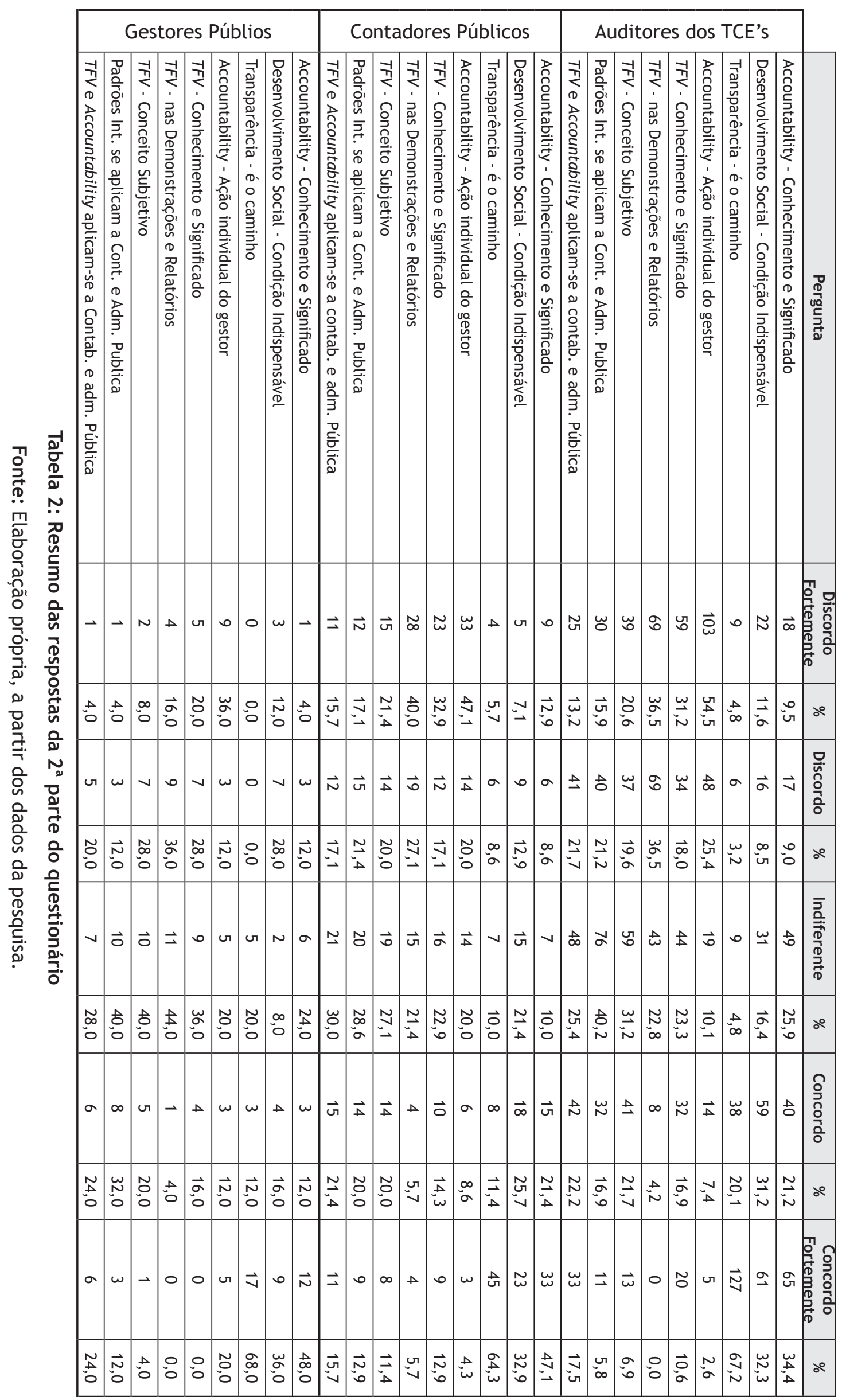




\subsection{AUDITORES DE CONTAS PÚBLICAS DOS TCES}

\subsubsection{AUDITORES PÚBLICOS: Teste de Hipóteses "A"}

O primeiro grupo se deteve na validação dos respondentes segregados por categoria, conforme exposto abaixo, para os que são auditores de Tribunais de Contas Estaduais, e teve como condição sine qua non aqueles que estão desempenhando suas funções nas equipes de auditoria. Após a identificação das respostas válidas, a partir do output do SPSS, objetivando encontrar o valor do teste estatístico Qui-Quadrado, combinado ainda com o Teste Kruskal-Wallis, e por meio dele, executado a partir do aplicativo estatístico SPSS, verificou-se que ele seguia o mesmo norte apontado pelo Qui-Quadrado.

A primeira decisão é de rejeitar $\mathrm{HOa}$, na ótica dos auditores dos TCEs, ou seja, os padrões internacionais de contabilidade são aplicados à contabilidade pública brasileira. Esta decisão se deu em virtude dos testes de Qui-Quadrado e KruskalWallis calculados terem apresentado valores maiores do que os tabelados, fato esse que, em consonância com a teoria estatística, enseja a rejeição da hipótese nula, conforme aponta Hackbarth Neto e Stein (2003, p. 6) "[...] comparar o valor real com o valor teórico do teste. Se Qui calculado for menor que Qui tabelado não se pode rejeitar a hipótese nula."

Essa afirmação, por sua vez, vai de encontro com o apontado nas respostas, quando $37 \%$ discordam ou discordam fortemente, $40,2 \%$ se mostram indiferentes e $22,7 \%$ concordaram com a aplicação desse padrão. Outro fato que chama atenção nesse caso é a Moda dessa distribuição ser 3, ou seja, aquela onde o respondente se mostrava indiferente ao que era apontado, fato que ainda era verificado. É que, ao ter uma média aritmética de 2,76, o desvio-padrão de 1,094 e a variância de 1,196 mostra que a distribuição se fez com, no máximo, concordar ou discordar, fato que referencia a dúvida que pairou sobre a possibilidade ou não de se aplicar os padrões aqui no Brasil, na ótica dos auditores de contas públicas dos TCEs, quando afirmavam que conheciam o termo accountability.

\begin{tabular}{|c|c|c|c|c|c|c|c|}
\hline \multirow{2}{*}{$\begin{array}{c}\text { Grupo: } \\
\text { Auditores dos TCEs }\end{array}$} & \multicolumn{3}{|c|}{ Teste Qui-Quadrado* } & \multicolumn{3}{|c|}{ Teste Kruskal - Wallis } & \multirow[b]{2}{*}{ Decisão } \\
\hline & $\mathrm{QUI}_{\mathrm{tab}}$ & $\mathrm{QUI}_{\mathrm{cal}}$ & $\begin{array}{l}\text { Asymp. Sig. } \\
\text { (NS=5\%) }\end{array}$ & $\mathrm{QUI}_{\mathrm{tab}}$ & $\mathrm{H}_{\mathrm{cal}}$ & $\begin{array}{l}\text { Asymp. Sig. } \\
\text { (NS=5\%) }\end{array}$ & \\
\hline $\begin{array}{l}\text { Conhecimento de } \\
\text { accountability }\end{array}$ & 3,841 & 5,174 & 0,023 & 3,841 & 6,247 & 0,012 & $\begin{array}{l}\text { Rejeitar } \\
\mathrm{HOa}\end{array}$ \\
\hline $\begin{array}{c}\text { Conhecimento de true } \\
\text { and fair view }\end{array}$ & 3,841 & 2,378 & 0,123 & 3,841 & 3,178 & 0,075 & Aceitar $\mathrm{HOa}$ \\
\hline
\end{tabular}

Tabela 3: Teste de Hipóteses: Os padrões internacionais de contabilidade são adequados para aplicação nas entidades da administração pública brasileira - Auditores TCEs.

Fonte: Elaboração própria, a partir dos dados da pesquisa.

Ao se analisarem aqueles que se diziam conhecedores do conceito/doutrina true and fair view, a decisão foi aceitar $\mathrm{HOa}$, ou seja, neste ponto foram consonantes 
as respostas verificadas pela análise descritiva e a dos testes matemáticos, fato que poderá ser considerado como um indício das dificuldades para a convergência das NBC TSP às IPSAS. Fez-se ainda para este mesmo grupo o questionamento relacionado à aplicabilidade destes dois conceitos em especial, accountability e true and fair view, na contabilidade pública brasileira, e obtiveram-se os seguintes resultados: no que tange ao teste do Qui-Quadrado para auditores de TCEs, dos 189 (cento e oitenta e nove) respondentes, apenas 105 (cento e cinco) tiveram valor estatístico quanto ao crosstabulation entre os que afirmaram conhecerem e saberem o que significa o termo accountability e a aplicabilidade dos conceitos accountability e true and fair view à contabilidade pública brasileira, o que ocasionou um missing de $44,4 \% \mathrm{em}$ função da opção pela indiferença nas questões relacionadas.

Fato que também foi identificado foi o crosstabulation entre os que afirmaram conhecerem e saberem o que significa o termo true and fair view e a aplicabilidade dos padrões internacionais de contabilidade a contabilidade pública brasileira, 0 que ocasionou um missing de $42,9 \%$, ou seja, 81 (oitenta e um) respondentes. 0 segundo passo foi à apresentação do Crosstabulation Accountability - Conheço este termo e sei o que significa * Estes conceitos true and fair view (visão verdadeira e apropriada) e accountability são aplicáveis na contabilidade e gestão pública brasileira (Tabela 64) e do Crosstabulation True and Fair View (Visão Verdadeira e Apropriada) - Conheço este termo e sei o que significa * Estes conceitos true and fair view (visão verdadeira e apropriada) e accountability são aplicáveis na contabilidade e gestão pública brasileira.

\subsubsection{AUDITORES PÚBLICOS: Teste de Hipóteses “B”}

Após a apresentação das respostas válidas, a partir do output do SPSS, objetivouse encontrar o valor do teste estatístico Qui-Quadrado, que foi um dos testes utilizados. Objetivando dar embasamento estatístico, aplicou-se o teste de Kruskal-Wallis, pelo qual se obtiveram as respostas abaixo, onde para o Crosstabulation Accountability Conheço este termo e sei o que significa * Estes conceitos true and fair view (visão verdadeira e apropriada) e accountability são aplicáveis na contabilidade e gestão pública brasileira, foram validados 105 questionários, enquanto no Crosstabulation True and Fair View (Visão Verdadeira e Apropriada) - Conheço este termo e sei o que significa * Estes conceitos true and fair view (visão verdadeira e apropriada) e accountability são aplicáveis na contabilidade e gestão pública brasileira, validaramse 108 questionários, fato que foi também verificado quando do teste do QuiQuadrado.

Após a obtenção desses resultados, os mesmos foram reunidos em uma tabela onde se buscava evidenciar a decisão a ser tomada mediante a aplicação dos testes estatísticos, e verificou-se que, para aqueles que conhecem tanto o conceito/doutrina accountability quanto o true and fair view, a aplicação dos dois conceitos/doutrinas true and fair view (visão verdadeira e apropriada) e accountability à contabilidade e gestão pública brasileira é sim possível, já que, de acordo com a teoria estatística, a decisão de rejeitar HOb pressupõe que são aplicáveis, fato que é referenciado 
pelos dados descritivos, ou seja, 34,9\% discordam ou discordam fortemente, $25,4 \%$ se mostra indiferentes, já 39,7\% concordam ou concordam fortemente, sinalizando que tais conceitos são aplicáveis, conforme Tabela 4 abaixo.

\begin{tabular}{|c|c|c|c|c|c|c|c|}
\hline \multirow{2}{*}{$\begin{array}{c}\text { Grupo: } \\
\text { Auditores dos TCEs }\end{array}$} & \multicolumn{3}{|c|}{ Teste Qui-Quadrado* } & \multicolumn{3}{|c|}{ Teste Kruskal - Wallis } & \multirow[b]{2}{*}{ Decisão } \\
\hline & $\mathrm{QUI}_{\mathrm{tab}}$ & $\mathrm{QUI}_{\text {cal }}$ & $\begin{array}{l}\text { Asymp. Sig. } \\
\text { (NS=5\%) }\end{array}$ & $\mathrm{QUI}_{\mathrm{tab}}$ & $\mathrm{H}_{\text {cal }}$ & $\begin{array}{l}\text { Asymp. Sig. } \\
\text { (NS=5\%) }\end{array}$ & \\
\hline $\begin{array}{l}\text { Conhecimento de } \\
\text { accountability }\end{array}$ & 3,841 & 12.943 & 0,000 & 3,841 & 14,509 & 0,000 & Rejeitar HOb \\
\hline $\begin{array}{l}\text { Conhecimento de } \\
\text { true and fair view }\end{array}$ & 3,841 & 8,240 & 0,004 & 3,841 & 9,315 & 0,002 & Rejeitar HOb \\
\hline
\end{tabular}

* Teste com a Correção de Yates.

Tabela 4: Teste de Hipóteses: Estes conceitos true and fair view (visão verdadeira e apropriada) e accountability são aplicáveis na contabilidade e gestão pública brasileira Auditores dos TCEs

Fonte: Elaboração própria, a partir dos dados da pesquisa.

\subsection{CONTADORES PÚBLICOS}

\subsubsection{CONTADORES PÚBLICOS: Teste de Hipóteses "A"}

Ao se analisarem os contadores públicos, efetuou-se o teste do Qui-Quadrado e, dos 70 (setenta) respondentes, apenas 46 (quarenta e seis) tiveram validade estatística, de acordo com os parâmetros de verdade e consistência entre as respostas para o crosstabulation entre os que afirmaram conhecerem e saberem o que significa o termo accountability e a aplicabilidade dos padrões internacionais de contabilidade à contabilidade pública brasileira, o que ocasionou um missing de $34,3 \%$, que corresponde a 24 (vinte e quatro) questionários. No crosstabulation realizado entre aqueles que afirmaram conhecerem e saberem o que ele significa o termo true and fair view e a aplicabilidade dos padrões internacionais de contabilidade à contabilidade pública brasileira, ocasionou-se um missing de 45,7 \%, ou seja, 32 (trinta e dois) respondentes.

Outra informação que é necessária para a análise e decisão quanto ao sistema de hipóteses diz respeito ao Crosstabulation Accountability - Conheço este termo e sei o que significa * Os padrões internacionais de contabilidade são adequados para aplicação nas entidades da administração pública brasileira, bem como o Crosstabulation True and Fair View (Visão Verdadeira e Apropriada) - Conheço este termo e sei o que significa * Os padrões internacionais de contabilidade são adequados para aplicação nas entidades da administração pública brasileira. Essas informações são apresentadas mostrando a comparação entre o que se esperava, e aquilo que aconteceu, conforme Tabela 75 abaixo:

Por fim, na busca por referendar o estudo por meio de uma validade estatística, utilizou-se ainda o Teste Kruskal-Wallis executado a partir do aplicativo estatístico SPSS, e por meio dele verificou-se que ele seguia o mesmo norte apontado pelo 
Qui-Quadrado. Ao se tratarem todos os dados coletados, estes deram subsídios para a elaboração da Tabela 5 abaixo, que sintetiza o sistema de hipóteses e aponta a decisão a ser tomada mediante a análise dos resultados:

\begin{tabular}{|c|c|c|c|c|c|c|c|}
\hline \multirow{2}{*}{$\begin{array}{l}\text { Grupo: } \\
\text { Contadores Públicos }\end{array}$} & \multicolumn{3}{|c|}{ Teste Qui-Quadrado* } & \multicolumn{3}{|c|}{ Teste Kruskal - Wallis } & \multirow[b]{2}{*}{ Decisão } \\
\hline & $\mathrm{QUI}_{\mathrm{tab}}$ & $\mathrm{QUI}_{\text {cal }}$ & $\begin{array}{l}\text { Asymp. Sig. } \\
\text { (NS=5\%) }\end{array}$ & $\mathrm{QUI}_{\text {tab }}$ & $\mathrm{H}_{\text {cal }}$ & $\begin{array}{l}\text { Asymp. Sig. } \\
\text { (NS=5\%) }\end{array}$ & \\
\hline $\begin{array}{l}\text { Conhecimento de } \\
\text { accountability }\end{array}$ & 3,841 & 3,460 & 0,063 & 3,841 & 4,656 & 0,031 & Aceitar $\mathrm{HOa}$ \\
\hline $\begin{array}{c}\text { Conhecimento de true } \\
\text { and fair view }\end{array}$ & 3,841 & 2,993 & 0,084 & 3,841 & 4,226 & 0,040 & Aceitar $\mathrm{HOa}$ \\
\hline
\end{tabular}

* Teste com a Correção de Yates.

Tabela 5: Teste de Hipóteses: Os padrões internacionais de contabilidade são adequados para aplicação nas entidades da administração pública brasileira - Contadores Públicos Fonte: Elaboração própria, a partir dos dados da pesquisa.

Os resultados apontam que deverá ser aceita $\mathrm{HOa}$, em virtude de o resultado calculado do Qui-Quadrado ser menos que o resultado tabelado e de este ter um nível de significância, enquanto o Kruskal-Wallis não dispõe dessa significância, mesmo tendo resultado ao contrário. Esse resultado é consonante com o resultado verificado na etapa descritiva, em que 38,6\% discordaram da adequabilidade desses padrões para a contabilidade brasileira, $28,6 \%$ se declararam indiferentes e $32,9 \%$ concordaram com a aplicação. Essa decisão contribui ainda mais para a tese de que o processo de convergência poderá vir a ter dificuldades de implementação.

Este grupo respondeu ainda a um questionamento quanto à aplicabilidade destes dois conceitos em especial, accountability e true and fair view, na contabilidade pública brasileira, e apreendeu-se deles os seguintes resultados: quando da opção em aplicar o teste do Qui-Quadrado, dos 70 (setenta) contadores públicos respondentes, apenas 44 (quarenta e quatro) obtiveram valor estatístico; quanto ao crosstabulation entre os que afirmaram conhecerem e saberem o que significa o termo accountability e a aplicabilidade dos conceitos accountability e true and fair view à contabilidade pública brasileira, ocasionou-se um missing de $37,1 \%$.

\subsubsection{CONTADORES PÚBLICOS: Teste de Hipóteses “B”}

Foi gerado um missing de não validade estatística de $42,9 \%$, quando da análise do crosstabulation entre os que afirmaram conhecerem e saberem o que significa o termo true and fair view e a aplicabilidade dos padrões internacionais de contabilidade à contabilidade pública brasileira. Ao se apresentarem o Crosstabulation Accountability - Conheço este termo e sei o que significa * Estes conceitos true and fair view (visão verdadeira e apropriada) e accountability são aplicáveis na contabilidade e gestão pública brasileira, e o Crosstabulation True and Fair View 
(Visão Verdadeira e Apropriada) - Conheço este termo e sei o que significa * Estes conceitos true and fair view (visão verdadeira e apropriada) e accountability são aplicáveis na contabilidade e gestão pública brasileira, encontrou-se que, segundo o cálculo estatístico, era esperado um grupo de respostas, fato este que não ocorreu.

Aplicou-se ainda o teste de Kruskal-Wallis, pelo qual se obtiveram as respostas abaixo, onde para o Crosstabulation Accountability - Conheço este termo e sei o que significa * Estes conceitos true and fair view (visão verdadeira e apropriada) e accountability são aplicáveis na contabilidade e gestão pública brasileira, foram validados 44 (quarenta e quatro) questionários, enquanto no Crosstabulation True and Fair View (Visão Verdadeira e Apropriada) - Conheço este termo e sei o que significa * Estes conceitos true and fair view (visão verdadeira e apropriada) e accountability são aplicáveis na contabilidade e gestão pública brasileira, validou-se 40 (quarenta) questionários, fato que foi também verificado quando do teste do Qui-Quadrado.

Os resultados encontrados orientaram para a construção de uma tabela com vistas a facilitar e melhorar a exposição e posterior decisão. Contatou-se que, para aqueles que conhecem o conceito/doutrina accountability, a aplicação dos dois conceitos/doutrinas true and fair view (visão verdadeira e apropriada) e accountability são a contabilidade e gestão pública brasileira, é sim possível, já que, de acordo com a teoria estatística, a decisão foi de rejeitar HOb, pressupondo que são aplicáveis. Já para aqueles que conhecem o true and fair view, a decisão estatística foi a de aceitar a hipótese nula, fato que destoa do que foi referenciado pelos dados descritivos, ou seja, 32,9\% discordam, enquanto $30 \%$ são indiferentes e $37,1 \%$ se mostraram favoráveis, sinalizando que tais conceitos são aplicáveis.

\begin{tabular}{|c|c|c|c|c|c|c|c|}
\hline \multirow{2}{*}{$\begin{array}{l}\text { Grupo: } \\
\text { Contadores } \\
\text { Públicos }\end{array}$} & \multicolumn{3}{|c|}{ Teste Qui-Quadrado* } & \multicolumn{3}{|c|}{ Teste Kruskal - Wallis } & \multirow[b]{2}{*}{ Decisão } \\
\hline & $\mathrm{QUI}_{\mathrm{tab}}$ & $\mathrm{QUI}_{\text {cal }}$ & $\begin{array}{l}\text { Asymp. Sig. } \\
\text { (NS=5\%) }\end{array}$ & $\mathrm{QUI}_{\mathrm{tab}}$ & $\mathrm{H}_{\mathrm{cal}}$ & $\begin{array}{l}\text { Asymp. Sig. } \\
\text { (NS=5\%) }\end{array}$ & \\
\hline $\begin{array}{l}\text { Conhecimento de } \\
\text { accountability }\end{array}$ & 3,841 & 6,537 & 0,011 & 3,841 & 8,194 & 0,004 & Rejeitar $\mathrm{HOa}$ \\
\hline $\begin{array}{l}\text { Conhecimento } \\
\text { de true and fair } \\
\text { view }\end{array}$ & 3,841 & 0,318 & 0,573 & 3,841 & 0,783 & 0,376 & Aceitar $\mathrm{HOa}$ \\
\hline
\end{tabular}

* Teste com a Correção de Yates.

Tabela 6: Teste de Hipóteses: Estes conceitos true and fair view (visão verdadeira e apropriada) e accountability são aplicáveis na contabilidade e gestão pública brasileira - Contadores Públicos

Fonte: Elaboração própria, a partir dos dados da pesquisa.

\subsection{GESTORES PÚBLICOS}

Ao se executar os testes estabelecidos na metodologia do presente trabalho, verificou-se que os dados referentes ao grupo de respondentes gestores públicos não dispõe de validade estatística, visto que três células, ou seja, $75 \%$ da amostra, 
obteve frequência esperada mínima menor que 1, já que, dos 25 (vinte e cinco) respondentes, 13 (treze) foram excluídos do cômputo dos respondentes, em virtude de se declararem indiferentes.

\section{CONSIDERAÇÕES FINAIS}

Este artigo trilhou o caminho visando evidenciar a percepção dos auditores dos TCEs, dos gestores e contadores públicos dos Estados de Pernambuco e da Paraíba quanto à aplicabilidade dos conceitos true and fair view e accountability na contabilidade pública brasileira e sua influência no processo de convergência com os padrões internacionais de contabilidade aplicados ao setor público, processo este que deverá nos próximos anos modificar totalmente o foco da contabilidade pública brasileira, conforme se expõe a seguir.

Considerando que atualmente vive-se um estágio de profunda mudança desencadeada desde as audiências públicas visando à edição das NBC TSP, com a publicação da Portaria n ${ }^{\circ} 184 / 08$ do Ministério da Fazenda, e, principalmente, do desejo dos profissionais por uma contabilidade com feições mais delineadas pela ciência contábil e cada vez menos pelo orçamento público, regido em sua essência por normativos legais e sem apresentar aos diversos usuários informações capazes de serem completas e distantes do privilégio a um único grupo usuário. Esse movimento é capitaneado por diversos pensadores da contabilidade pública brasileira, em parceria com os órgãos envolvimentos no processo, como: STN, CFC, TCE / TCU e pela academia.

Considerando que ao se analisar a percepção desses três grupos, apenas se consegue verificar, com validade estatística, dois, ou seja, dos auditores dos TCEs, dos contadores e dos gestores públicos, apenas os auditores dos TCEs e contadores públicos obtiveram validade estatística quando da aplicação dos testes Qui-Quadrado e Kruskal-Wallis.

Considerando que esse resultado levou a conclusões com a percepção desses dois grupos envolvidos no processo: quando estão segregados em função do seu conhecimento de accountability, os auditores públicos acreditam que são aplicáveis à contabilidade pública brasileira os padrões internacionais de contabilidade e os conceitos/doutrinas accountability e true and fair view, já os contadores públicos divergem apenas no que tange à aplicação dos padrões, pois eles não acreditam neles.

Quando eles estão segregados em função do conhecimento em true and fair view, os auditores não acreditam nos padrões e acreditam nos conceitos/doutrinas, já os contadores não acreditam em nenhuma das possibilidades de aplicação, quer seja dos conceitos/doutrinas, quer seja nos padrões internacionais de contabilidade. Essa afirmação estatística destoa em alguns momentos do que se pode verificar quando da análise do gráfico na Figura 7 abaixo, construído a partir de uma perspectiva descritiva apenas, onde se tem uma ligeira maioria sinalizando que tais conceitos são aplicáveis. 


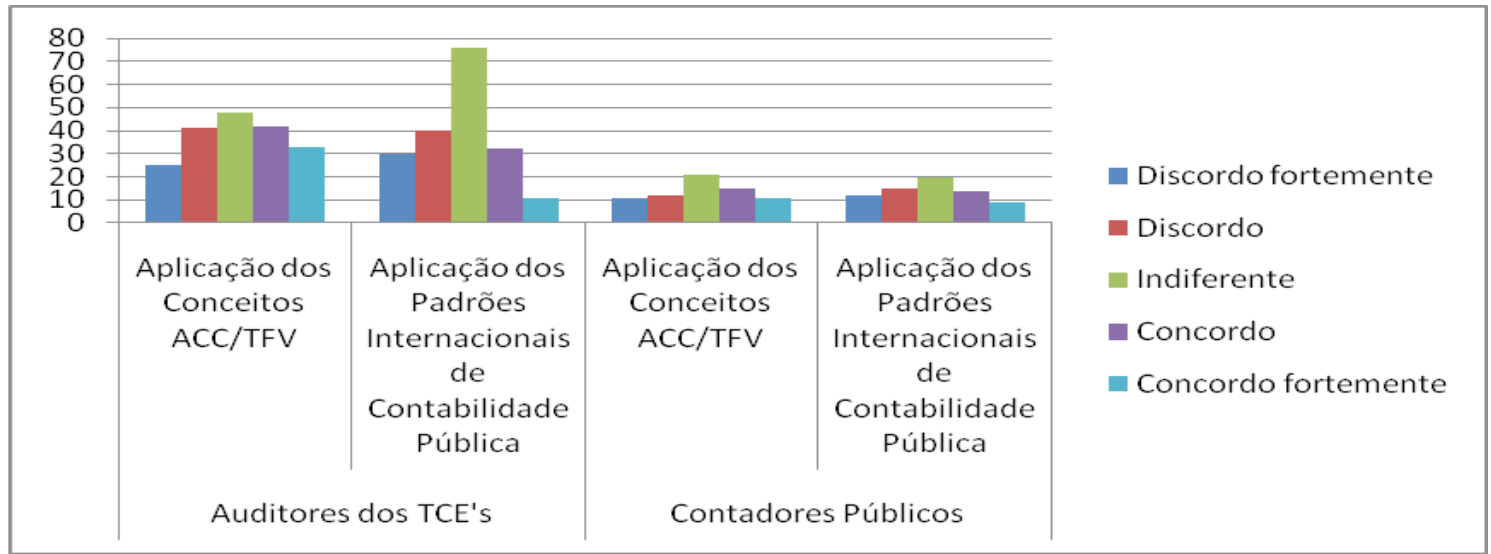

Figura 1: Respostas dos auditores e contadores públicos Fonte: Dados da pesquisa

Considerando que se deve ter a academia no papel de formadora e fomentadora de novas pesquisas e estudos e, ao abrir mais espaços, formará não apenas novos profissionais, mas contribuirá com a propagação dessa nova contabilidade pública, alinhada com os preceitos da ciência contábil, bem como tais pesquisas possibilitarão uma divulgação ampla e eficaz desse processo.

Considerando que o referencial teórico apontou pontos que denotam empecilhos ao processo como as reformas do Estado que ainda não se completaram, o sistema jurídico/legal codificado (code law), a cultura tanto do povo como organizacional em um país de dimensões continentais e que não está habituado com a responsabilidade atribuída pelo do subjetivismo, deverão ser responsáveis do ponto de vista da aplicabilidade do arcabouço teórico da chamada "contabilidade pública patrimonial".

Do estudo apresentado pode-se afirmar que o processo de convergência deverá ter incorporado à sua agenda esforços no sentido de promover uma conscientização mais eficaz, envolvendo não apenas os profissionais que se obrigam a participar por estarem intimamente ligados à área pública, mas sim uma presença dos demais atores do processo e principalmente daqueles que serão os desbravadores desse novo caminho.

Outro ponto a ser trabalhado é na verificação das formas de se prevenirem os fatores dificultadores do processo de convergência das NBC TSP às IPSAS. Há necessidade de se terem todos os grupos participando desse processo, por exemplo, os gestores públicos, pois não se poderá deixar esse processo à discricionariedade dos mesmos, bem como sem que eles promovam uma participação, debate e implementação das diretrizes estabelecidas pelos comandantes deste processo.

Essa posição tomada pelos respondentes, quanto à aplicabilidade dos padrões e dos conceitos/doutrinas, denotam possíveis dificuldades a serem enfrentadas no decorrer do proceso de convergência, em face da não aplicação dos novos parâmetros de reconhecimento, mensuração e avaliação dos fatos contábeis, a partir da contabilidade pública patrimonial. 
No que tange aos direcionadores macro dessa estratégia, evidencia-se a necessidade de um programa sistemático que proporcione, aos municípios e aos estados menores, capacidade de implantação desse novo modelo, aliado com uma consientização, por parte dos órgãos de controle externo, em adotarem uma política de educar e não de de punir nessa fase inicial do processo. Fato este que passa desde o plano de contas único, que já é discutido no âmbito federal e que dispõe de cronograma discutido para estados e municípios.

Ao final do estudo, chegou-se à conclusão de que para serem percebidas pela população em geral as boas práticas de gestão e contabilidade pública, vistas em nível mundial, bem como as transformações resultantes da mudança do foco para a contabilidade patrimonial, necessitam de "desenvolvimento social", aliado a um maior grau de "transparência". No que tange ao processo de convergência, este deverá ter incorporado à sua agenda esforços, ações capazes de promover uma conscientização eficaz, bem como, ter o envolvimento de profissionais, gestores e sociedade neste processo, outro fato é que a falta de conhecimento a cerca destes termos e do que representa o processo de convergência como um todo para nosso país, ainda será um grande empecilho.

A título de limitação do estudo, aponta-se a abrangência geográfica, no país continental que é o Brasil, onde apenas se trabalharam os estados de Pernambuco e da Paraíba, ficando neste quesito a sugestão de replicação do estudo em outros estados.

Outro fator se refere ao momento que se inicia esta pesquisa, quando ainda não se tinha uma ampla divulgação do processo de convergência, fato este que pode motivar uma influência nociva aos resultados, que aqui se trata como balizador do contexto desafiador pelo qual passaram os desbravadores deste processo e que outros pesquisadores irão enfrentar no desenrolar das pesquisas científicas que nortearão e servirão de base durante o processo de convergência das NBC T SP às IPSAS.

Por fim, aponta-se o fator restritivo dos que trabalham com contabilidade pública (contadores públicos e gestores públicos) que não manifestaram desejo em participar da pesquisa, mesmo com o envio sistemático de solicitações em meio eletrônico, por meio do cadastro de gestores e contadores públicos do TCE-PB, dos sites do governo dos estados de Pernambuco e da Paraíba, das prefeituras e câmaras municipais, bem como outras formas de solicitação por escrito.

Sugere-se então que haja uma definição estratégica por parte dos órgãos capitaneadores desse processo em nível de Brasil, visando fomentar a participação desses agentes públicos no processo de convergência.

Como sugestões de outras pesquisas, apresentam-se dois flancos, um balizado pela replicação do estudo abrangendo os demais estados do país e o outro que busque colher as percepções dos gestores públicos que de certa forma ausentaramse desta pesquisa, pois aqui foram apenas representados por 25 (vinte e cinco) respondentes. 


\section{REFERÊNCIAS}

AMARO, Ana; PÓVOA, Andreia; MACEDO, Lúcia. A arte de fazer questionários. Porto, 2004/2005. Disponível em: <http://www.jcpaiva.net/getfile.php?cwd=ensino/ cadeiras/metodol/2004 2005/894dc/f94c1\&f=a9308>. Acesso em: 16 ago. 2008.

BRASIL. Ministério da Fazenda. Portaria $n^{\circ}$ 184, de 25 de agosto de 2008. Dispõe sobre as diretrizes a serem observadas no setor público (pelos entes públicos) quanto aos procedimentos, práticas, laboração e divulgação das demonstrações contábeis, de forma a torná-los convergentes com as Normas Internacionais de Contabilidade Aplicadas ao Setor Público. Disponível em: <http://www.fazenda.gov.br/portugues/ legislacao/portarias/2008/ portaria184.asp>. Acesso em: 15 out. 2009.

CAMPOS, Anna Maria. Accountability: Quando podemos traduzi-la para o português? Revista de Administração Pública. Rio de Janeiro. v. 24, n. 2, p. 30-50, fev./abr. 1990.

CASTRO, Domingos Poubel. Ajustando o foco da Contabilidade Pública. Revista Brasileira de Contabilidade, Brasília, ano XXXIV, n. 151, p 69-83, jan./fev. 2005.

FLORIANI, Dimas. Brésil: à qui profite La reforme de l'Etat? In: LA PENSÉE COMPTABLE - ÉTAT, NÉOLIBÉRALISME, NOUVELLE GESTION PUBLIQUE. Les Nouveaux Cahiers de L`Institut Universitaire D 'Études du Développement. Paris: Presses Universitaires de France, 1998.

HACKBARTH NETO, Arthur Alexandre. STEIN, Carlos Efrain. Uma abordagem dos testes não-paramétricos com utilização do excel. 2003 Disponível em: < www.mat. ufrgs.br/ viali/estatistica/.../artigo_11_09_2003.pdf> Acesso em 07 JUN 2009.

IFAC. International Federation of Accountants. Study 13: Governance in the Public Sector: A Governing Body Perspective International Public Sector Study, 2001.

JREIGE, Elionor F. True and fair view: Um entrave ou um impulso para a contabilidade? Caderno de Estudos FEA USP, São Paulo, v. 10, n. 17, p. 35-46, 1998. Disponível em: $<$ www.eac.fea.usp.br/cadernos/completos/cad17/index_arquivos/titu3.pdf>Acesso em: 14 out. 2007.

MARTINEZ, Vinício C.. Estado de Direito. Jus Navigandi, Teresina, ano 10, n. 918, 7 jan. 2006. Disponível em: <http://jus2.uol.com.br/doutrina/texto.asp?id=7786>. Acesso em: 18 out. 2008.

OLIVERAS, Ester; AMAT, Oriol. Influencia de la cultura en la contabilidad de gestión: El caso de España. 2004. Disponível em: <http://www.oriolamat.cat/files/ dimensions_national_culture_and_accounting_environment.doc>. Acesso em: 6 set. 2009.

PINHEIRO, Paulo Bekmessian; NAKAGAWA, Masayuki. Origem Genética da Contabilidade. In: CONGRESSO USP INICIAÇÃO CIENTÍFICA EM CONTABILIDADE, 1.; CONGRESSO USP DE CONTROLADORIA E CONTABILIDADE, 4., 2004, São Paulo. Anais... São Paulo: EAC/ FEA/USP, 2004. Disponível em: <www.congressoeac.locaweb.com. br/artigos12004/143.pdf> Acesso em: 15 out. 2007.

RIBEIRO FILHO, José Francisco. Da aprovação das NBCASP pelo CFC à Convergência com as Normas Internacionais: Diretrizes, Estratégias e Próximos Passos. Belo 
Horizonte. 2008 Disponível em < www.cfc.org.br/uparq/francisco_ribeiro.ppt> Acesso em 10 MAR 2009

REVOREDO, Márcia Maria Oliveira. Brasil rumo aos padrões internacionais de contabilidade para o setor público: uma análise sob a ótica do Financial Management Reform Process Model de Lüder. 2008. 172 f. Dissertação (Mestrado em Ciências Contábeis) - Faculdade de Administração e Finanças, Universidade Estadual do Rio de Janeiro, Rio de Janeiro, 2008.

SCHEDLER, Andréas. Conceptualizing accountability. In: SCHEDLER, Andreas, DIAMOND, Larry. PLATTNER, Marc F. (eds.) The sel-Restraining State. Power and Accountability in new democracies. Boulder and London: Lynne Rienner Publishers, 1999.

SIFFERT FILHO, N. F. A teoria dos contratos econômicos e a firma. 1996. Tese (Doutorado em Controladoria e Contabilidade) - Faculdade de Economia, Administração e Contabilidade da Universidade de São Paulo, São Paulo, 1996.

SILVA, Lino Martins da. Contabilidade governamental: um enfoque administrativo da nova contabilidade pública. 8. ed. São Paulo: Atlas, 2009a.

- Contabilidade pública: ênfase no patrimônio x questão da legalidade. Disponível em: <www.cfc.org.br/uparq/p_lino.ppt>. Acesso em: 31 maio 2008a.

. NBCASP: A grande reforma na contabilidade pública. 2008b Disponível em: <http: / / linomartins.wordpress.com/2008/12/03/nbcasp-a-grande-reforma-nacontabilidade-publica/>. Acesso em: 20 jan. 2009.

. Projeto de Dissertação do Mestrado da UFPE - Orientador Prof. Jorge Lopes. [mensagem pessoal] Mensagem recebida por João Marcelo Alves Macêdo. Recife, 9 jun. 2009b.

- Relaxamento das normas de contabilidade: o papel dos organismos internacionais de contabilidade. 2009c. Disponível em: <http://linomartins. wordpress.com/2009/06/01/relaxamento-das-normas-de-contabilidade-o-papeldos-organismos-internacionais-de-contabilidade>. Acesso em: 9 jul. 2009.

- CONTABILIDADE PÚBliCA: DESAFIOS PARA UMA TRANSIÇÃO SEGURA. 2010. DISPONÍVEL EM: <HTTP://LINOMARTINS.WORDPRESS.COM/2010/04/20/ CONTABILIDADE-PUBLICA-DESAFIOS-PARA-UMA-TRANSICAO-SEGURA/>. ACESSO EM: 14 JUN. 2010.

SOARES, Rute Cristina Meurer. Estudo das diferenças culturais como empecilho à harmonização contábil: casos do Brasil, EUA e Japão. 2005. 132 f. Dissertação (Mestrado em Ciências Contábeis) - Universidade Regional de Blumenau, Blumenau, 2005. Disponível em: <proxy.furb.br/tede/tde_busca/arquivo.php?codArquivo=311>. Acesso em: 12 set. 2009.

WEFFORT, Elionor Farah Jreige. O Brasil e a harmonização contábil internacional: influências dos sistemas jurídico e educacional, da cultura e do mercado. São Paulo: Atlas, 2005. 231 p. Tese (Doutorado em Controladoria e Contabilidade) - Departamento de Contabilidade e Atuária, FEA-USP, 2005. 


\section{ENDEREÇOS DOS AUTORES:}

\section{João Marcelo Alves Macêdo}

Universidade Federal de Campina Grande

Unidade Academica de Ciências Contábeis - UACC

Rua Sinfronio Nazaré, 38, Centro - Sousa, PB - Brasil

58800-000

\section{Jorge Expedito de Gusmão Lopes}

Universidade Federal de Pernambuco

Centro de Ciências Sociais Aplicadas, Departamento de Ciências Contábeis

Av. dos Economistas, $\mathrm{s} / \mathrm{n}$ - Cidade Universitária

Recife, PE - Brasil

50740-580

\section{Lino Martins da Silva}

Universidade do Estado do Rio de Janeiro

Faculdade de Administração e Finanças

Rua São Francisco Xavier, 524, $9^{\circ}$ andar - Maracanã

Rio de Janeiro, RJ - Brasil

20550-900

José Francisco Ribeiro Filho

Universidade Federal de Pernambuco

Centro de Ciências Sociais Aplicadas, Departamento de Ciências Contábeis

Av dos Economistas, Departamento de Ciências Contábeis, 1o. andar sala E26 - CDU

Recife, PE - Brasil

50000-000

\section{Marcleide Maria Macedo Pederneiras}

Universidade Federal da Paraíba

Centro de Ciências Aplicadas e Educação

Campus IV do Litoral Norte - Centro

Mamanguape, PB - Brasil

58800-000

\section{Marcos Gilson Gomes Feitosa}

Universidade Federal de Pernambuco

Centro de Ciências Sociais Aplicadas

Rua Prof. Moraes Rego, 235

Cidade Universitária

Recife, PE - Brasil

50670-901 